KAWISTARA

VOLUME 5

No. 3, 22 Desember 2015

Halaman 221-328

\title{
KAJIAN WISATA BAHARI DI KAWASAN TUREDAWOLA WALO KABUPATEN NIAS UTARA
}

\author{
Meniato Telaumbanua \\ Dinas Kebudayaan, Pariwisata, Pemuda, dan Olahraga Kabupaten Nias Utara \\ Provinsi Sumatera Utara \\ Email: telaumbanua_meniato@yahoo.co.id \\ M. Baiquni \\ Fakultas Geografi Universitas Gadjah Mada
}

\begin{abstract}
The objectives of the research consisted of: (1) to identify the predominance of marine tourism activities and attractions in Turedawola Walo; (2) to analyze the degree of significance of activities and attractions, amenities, accessibility, local community conditions, safety, cleanliness and tourism information variables simultaneously and partially toward Turedawola Walo marine tourism quality; and (3) to examine the differences between direct and indirect participation of local community in the case of Turedawola Walo marine tourism development in North Nias Regency. This research was conducted in the village of Afulu, Afulu District, North Nias Regency by using a descriptive quantitative research method with the questionnaire addressed to 63 tourist/excursionist respondents and 80 local communities respondents used as samples. The results obtained were then processed and analyzed by using multiple linear regressions analysis to evaluate the significance and prove written hypotheses simultaneously and partially of seven factors affecting Turedawola Walo marine tourism quality and Mann-Whitney test to evaluate the differences between direct and indirect participation of local community in the case of Turedawola Walo marine tourism development. Results of the research indicated that: (1) the most predominant activities and tourist attractions in Turedawola Walo is surfing; (2) amenities, cleanliness and tourist information variables did not give significant contribution to the quality of Turedawola Walo marine tourism, while activities and attractions, accessibility, local community conditions, and tourism safety variables gave significant contribution to the quality of Turedawola Walo marine tourism; and (3) indirect participation greater than direct participation of local communities indicated that the majority of local community in Afulu village participated indirectly in the case of Turedawola Walo marine tourism development in North Nias Regency.
\end{abstract}

Keywords: Marine tourism; Tourism quality and products; Local community; Participation; Turedawola Walo-Afulu.

\section{ABSTRAK}

Tujuan penelitian terdiri atas: (1) mengindentifikasi keunggulan aktivitas dan atraksi wisata bahari di kawasan Turedawöla Walo; (2) menganalisis signifikansi pengaruh secara simultan dan parsial variabel aktivitas dan atraksi, amenitas, aksesibilitas, kondisi masyarakat lokal, keamanan, kebersihan dan informasi wisata terhadap Mutu Wisata Bahari di kawasan Turedawola Walo; dan (3) mengkaji perbedaan sifat partisipasi masyarakat dalam pengelolaan wisata bahari di kawasan Turedawola Walo 
Kabupaten Nias Utara. Penelitian ini dilakukan di Desa Afulu, Kecamatan Afulu, Kabupaten Nias Utara dengan menggunakan metode penelitian deskriptif kuantitatif. Pengumpulan data dilakukan dengan menggunakan metode survai dengan alat pengumpul data kuesioner terhadap 63 responden wisatawan/excursionists dan 80 responden masyarakat lokal yang digunakan sebagai sampel. Hasil yang diperoleh kemudian diolah dan dianalisis menggunakan uji regresi linier berganda untuk mengevaluasi signifikansi dan membuktikan hipotesis secara simultan dan parsial dari faktor-faktor yang mempengaruhi Mutu Wisata Bahari di kawasan Turedawola Walo dan uji Mann-Whitney untuk mengevaluasi perbedaan sifat partisipasi masyarakat. Berdasarkan hasil penelitian diketahui bahwa: (1) aktivitas dan atraksi wisata yang paling unggul di kawasan Turedawöla Walo adalah surfing; (2) variabel amenitas, kebersihan dan informasi wisata tidak berpengaruh secara signifikan terhadap Mutu Wisata Bahari di kawasan Turedawola Walo, sedangkan variabel aktivitas dan atraksi, aksesibilitas, kondisi masyarakat lokal, dan keamanan berpengaruh secara signifikan terhadap Mutu Wisata Bahari di kawasan Turedawola Walo; dan (3) perbedaan sifat partisipasi masyarakat diketahui bahwa partisipasi tidak langsung lebih besar daripada partisipasi langsung yang menandakan bahwa mayoritas masyarakat lokal Desa Afulu berpartisipasi secara tidak langsung terhadap pengelolaan wisata bahari Turedawola Walo Kabupaten Nias Utara.

Kata Kunci: Wisata bahari; Mutu dan produk wisata; Masyarakat local; Sifat partisipasi; Turedawola Walo-Afulu.

\section{PENGANTAR}

Indonesia merupakan negara kepulauan yang mempunyai pesisir dan lautan yang sangat luas, dengan garis pantai sepanjang $95.181 \mathrm{~km}$ dan 17.480 pulau (Idris, 2007). Indonesia merupakan salah satu negara kepulauan (Archipelagic State) terbesar yang memiliki garis pantai terpanjang kedua di dunia setelah Kanada dan mempesona, serta kehidupan laut yang kaya sumber daya alam tersebar di berbagai pulau kecil dan besar di seluruh penjuru nusantara (Numberi, 2009).

Baiquni (2004:128) bahwa otonomi mengandung sejumlah azas yang penting untuk diwujudkan pada setiap prosesnya. Azas kemajemukan adalah jawaban bagi otonomi yang menuntut pertimbangan matang kondisi (potensi) dan keadaan (perkembangan) daerah masingmasing. Asas keberlanjutan harus pula menjadi acuan otonomi, tidak hanya mempertimbangkan keadilan antar daerah dan antarkelompok masyarakat saat ini, tetapi mempertimbangkan pula generasi mendatang. Oleh karena itu, ada baiknya memahami kata bijak berikut ini: "Bumi bukan warisan dari nenek moyang kita, tetapi pinjaman dari anak cucu kita."

Kabupaten Nias Utara dibentuk berdasarkan Undang-Undang Nomor 45 Tahun 2008 tentang Pembentukan Kabupaten Nias Utara di Provinsi Sumatera Utara memiliki 11 Kecamatan 112 desa dan 1 kelurahan. Kabupaten ini diresmikan oleh Menteri Dalam Negeri Indonesia, Mardiyanto sebagai salah satu hasil pemekaran dari Kabupaten Nias pada 29 Oktober 2008. Sebagai daerah otonomi baru maka Kabupaten Nias Utara memiliki tanggungjawab untuk mengurus daerahnya baik dalam sisi pemerintahan maupun dalam mengelola sumber daya alam dan sumber daya manusia yang dimilikinya (BPS Nias, 2013).

Kabupaten Nias Utara merupakan salah satu daerah terluar Indonesia yang memiliki aset wisata bahari, aset keindahan alam dan aset budaya yang menakjubkan dan menarik yang dikenal oleh para wisatawan domestik dan mancanegara. Dalam Surat Keputusan Bupati Nias Utara Nomor: 556/219/K/Tahun 2013 tanggal 13 September 2013 tentang Penetapan Lokasi Objek Wisata dan Rekreasi di Kabupaten Nias Utara disebutkan 46 lokasi objek wisata yang dikelola oleh Pemerintah Kabupaten Nias Utara. Beberapa diantaranya berupa: (1) wisata bahari/pantai, misalnya Pantai Selancar Turedawola Walo, Pantai Indah Tureloto, Pantai Pasir Berbisik (Gawu Sifakiki), Pulau Wunga; (2) wisata alam, misalnya Puncak Hili Maziaya, Air Terjun Luaha Ndroi, Air Terjun Helewuti, Gua Wirö (aksen bahasa Nias), Danau Megötö; dan (3) wisata budaya, misalnya Rumah Adat Nias 
Utara Tugala Oyo, Tari Perang, Tari Maena, dan lain-lain. Salah satu lokasi yang berpotensi untuk dikembangkan sebagai kawasan wisata bahari yang relatif baru dan terus dirintis serta diupayakan menjadi spot selancar (surfing) berstandar mulai dari level daerah, nasional hingga internasional/dunia yaitu Kawasan Turedawola Walo (Desa Afulu, Kecamatan Afulu Kabupaten Nias Utara).

Pengelolaan dan pengembangan wisata bahari di kawasan Turedawola Walo masih dalam tahap awal/perintisan dan belum memberikan manfaat ekonomi secara optimal bagi masyarakat lokal. Faktor-faktor yang mempengaruhi lemahnya pengelolaan wisata bahari ini, yaitu (1) pemberdayaan masyarakat lokal masih belum terlaksana dengan baik sehingga menimbulkan rendahnya partisipasi dan kurangnya kesadaran masyarakat lokal dalam pengembangan wisata bahari di kawasan Turedawola Walo; (2) belum tersedianya/kurangnya sarana dan prasarana (amenitas) pendukung wisata bahari dan aksesibilitas; (3) tata kelola objek/ kawasan masih belum terlaksana dengan baik seperti: keterbatasan informasi wisata dan promosi wisata, kebersihan, keamanan objek wisata, agen perjalanan wisata, dan lain-lain sehingga kunjungan wisatawan masih sedikit. Berdasarkan uraian di atas, maka tujuan penelitian yang ingin dicapai sebagai berikut:

(1) Mengidentifikasi keunggulan aktivitas dan atraksi wisata bahari di kawasan Turedawola Walo Kabupaten Nias Utara.

(2) Menganalisis signifikansi pengaruh secara simultan dan parsial variabel aktivitas dan atraksi, amenitas, aksesibilitas, kondisi masyarakat lokal, keamanan, kebersihan, dan informasi wisata terhadap Mutu Wisata Bahari di kawasan Turedawola Walo Kabupaten Nias Utara.

(3) Mengkaji perbedaan sifat partisipasi masyarakat dalam pengelolaan wisata bahari di kawasan Turedawola Walo Kabupaten Nias Utara.

Undang-Undang RI Nomor 10 Tahun 2009 tentang Kepariwisataan pasal 1 ayat 1: Wisata adalah kegiatan perjalanan yang dilakukan oleh seseorang atau sekelompok orang dengan mengunjungi tempat tertentu untuk tujuan rekreasi, pengembangan pribadi, atau mempelajari keunikan daya tarik wisata yang dikunjungi dalam jangka waktu sementara. Selanjutnya, pasal 1 ayat 3: Pariwisata adalah berbagai macam kegiatan wisata dan didukung berbagai fasilitas serta layanan yang disediakan oleh masyarakat, pengusaha, pemerintah, dan Pemerintah Daerah.

Fandeli (2001) pariwisata adalah keseluruhan kegiatan serta proses yang berhubungan dengan perjalanan dan persinggahan orang-orang diluar tempat tinggalnya dantidak bermaksud mencarinafkah.Spillane (1994) pariwisata adalah perjalanan dari satu tempat ke tempat lain, bersifat sementara dilakukan perorangan maupun kelompok, sebagai usaha mencari keseimbangan atau keserasian dan kebahagiaan dengan lingkungan hidup dalam dimensi sosial, budaya, alam, dan ilmu.

Baiquni (2004), wisata bahari terkait dengan pengembangan potensi sumberdaya alam bahari pada wilayah yang potensial, hal ini bertujuan untuk mempercepat kegiatan pembangunan di daerah. Wilayah pinggiran dan pulau-pulau kecil dapat dibangun melalui keterlibatan dengan keterkaitan wisata bahari dalam upaya pemenuhan kebutuhan dasar ekonomi masyarakat. Nurisyah (2004) menyatakan bahwa wisata bahari merupakan salah satu implementasi dari kegiatan pemanfaatan jasa lingkungan yang sekaligus melindungi dan melestarikan sumber daya hayati, alam dan lingkungannya, serta meningkatkan perekonomian masyarakat setempat.

Adapun kegiatan wisata bahari meliputi: berjemur di pantai berpasir, renang, ski air, selancar angin (wind surfing), snorkeling, selam (diving), dan menelusuri tepian pantai yang kaya akan keanekaragaman hayati (Mann, 1982). Fandeli (1996) membagi aktivitas wisatawan yang dapat dilakukan di pantai, sebagai berikut: (1) aktivitas bentang laut (seascape), yaitu berenang, memancing, sampan atau dayung (berlayar), menyelam 
(diving dan snorkeling), selancar air, dan selancar angin serta berperahu (parasailing); dan (2) aktivitas bentang darat (coastal landscape) yaitu rekreasi meliputi olah raga susur pantai, bersepeda, panjat tebing pada dinding terjal pantai dan menelusuri gua pantai, bermain layang-layang, berkemah, berjemur, berjalan-jalan sambil menikmati pemandangan, dan berkuda atau naik dokar pantai. Jennings (2007:6), surfing dan selancar angin memiliki satu kesamaan: mereka bisa menjadi olahraga, rekreasi, pariwisata, atau pengalaman rekreasi, serta gaya hidup.

Aspek mutu pelayanan dan pengalaman wisata menunjuk pada kebutuhan pelayanan wisata untuk menghasilkan pengalaman total yang dinikmati wisatawan (total tourist's travel experiences) dalam hal-hal berikut (WTO, 2007:21 dalam Damanik dan Teguh, 2012): (1) pengembangan produk yang menawarkan jasa bermutu secara berkelanjutan. Produk dasar (atraksi, amenitas, aksesibilitas, dan hospitalitas); (2) menyusun paket produk dasar tersebut sedemikian rupa, sehingga dapat digunakan secara optimal dan memberikan nilai tambah (kepuasan berwisata); (3) menyediakan logistik untuk menjamin kemudahan dan kecepatan akses bagi wisatawan pada semua fasilitas pintu masuk destinasi; (4) teknis operasional layanan jasa yang bersentuhan secara langsung dengan aktivitas wisatawan, termasuk layanan transportasi (publik dan privat), pusat informasi wisata, akomodasi, makanan-minuman, atraksi, hiburan, layanan kesehatan, rekreasi dan kesenangan pribadi; dan (5) tindakan arif pascalayanan yang memberikan efek positif terhadap loyalitas dan pembentukan kesan baik (image building).

Suwena dan Widyatmaja (2010:90), amenities adalah segala macam prasarana dan sarana yang diperlukan oleh wisatawan selama berada di daerah tujuan wisata. Pitana (2009:130), aksesibilitas merupakan mudah atau sulitnya wisatawan menjangkau destinasi yang diinginkannya. Suwena dan Widyatmaja (2010:98), pelayanan tambahan (ancillary service) yaitu pelengkap yang harus disediakan oleh pemerintah daerah dari suatu DTW, baik untuk wisatawan maupun untuk pelaku pariwisata termasuk pemasaran, pembangunan fisik dan mengkoordinir segala aktivitas wisata, misalnya wisatawan memperoleh pelayanan informasi di Tourism Information Center (TIC), bahan cetak seperti brosur, buku, leaflet, poster, peta, dan lainlain. Jasa pendukung lainnya yang sangat penting adalah jasa pemandu.

Steck dkk (1999) dalam Damanik dan Weber (2006:108-109) mengelompokkan sifat partisipasi masyarakat berdasarkan derajat keterlibatan mereka dalam pengelolaan usaha pariwisata, seperti disederhanakan dalam Tabel 1 berikut:

Tabel 1

Sifat dan Parameter Partisipasi Masyarakat

\begin{tabular}{|c|c|}
\hline Sifat Partisipasi & Parameter \\
\hline Langsung & $\begin{array}{l}\text { 1. Masyarakat bekerja di dalam proyek (petugas parkir, keamanan, pemandu, } \\
\text { karyawan akomodasi/restoran) } \\
\text { 2. Masyarakat sebagai pengusaha atau pengelola jasa akomodasi atau restoran, } \\
\text { atraksi, dan transportasi di dalam kawasan proyek } \\
\text { 3. Masyarakat menikmati peluang untuk memperoleh pendidikan dan } \\
\text { pelatihan pengelolaan proyek } \\
\text { 4. Masyarakat menjadi tenaga pemasaran dan promosi dengan bekerjasama } \\
\text { dengan BPW dan tour operator }\end{array}$ \\
\hline Tidak Langsung & $\begin{array}{l}\text { 1. Masyarakat sebagai supplier bahan kebutuhan proyek pariwisata dalam bentuk: } \\
\text { a) bahan pangan (beras, sayur-mayur, buah-buahan, minuman, daging, } \\
\text { bunga-bungaan, ikan dan lain-lain; } \\
\text { b) bahan bangunan (ijuk, bambu, kayu, anyaman); } \\
\text { c) kerajinan tangan (ukiran, anyaman, lukisan, dan lain-lain); } \\
\text { 2. Masyarakat sebagai pengelola usaha jasa penunjang proyek pariwisata } \\
\text { (persewaan tenda, alat selam, bengkel) }\end{array}$ \\
\hline
\end{tabular}




\begin{tabular}{c|ll}
\hline Sifat Partisipasi & \multicolumn{1}{c}{ Parameter } \\
\hline Nol/Tidak ada & 2 & Masyarakat mendanai sendiri infrastruktur di sekitar lokasi proyek \\
& 3 & $\begin{array}{l}\text { Masyarakat membayar sendiri biaya pemanfaatan kawasan proyek (karcis } \\
\text { masuk, lisensi fotografi, dan lain-lain). }\end{array}$ \\
\hline
\end{tabular}

\{Sumber: Steck, dkk. (1999) dalam Damanik dan Weber, 2006\}

Pertama, untuk mengevaluasi keunggulan aktivitas dan atraksi wisata bahari di kawasan Turedawola Walo, maka peneliti memberikan kuesioner kepada wisatawan (mancanegara dan domestik)/excursionists yang secara kebetulan berkunjung di lokasi dan diolah secara kuantitatif deskriptif. Kedua, ketujuh faktor $\left(\mathrm{X}_{1} \rightarrow \mathrm{X}_{7}\right)$ yang mempengaruhi Mutu Wisata Bahari di kawasan Turedawola Walo (Y) dianalisis secara kuantitatif deskriptif dengan statistik regresi linier berganda untuk mengevaluasi tingkat signifikansi dari setiap faktor pengaruh atau setiap variabel bebas tersebut dari jawaban wisatawan (mancanegara dan domestik) atau excursionists yang secara kebetulan sedang berkunjung di lokasi wisata. Ketiga, untuk mengetahui bagaimana masyarakat berpartisipasi, maka perlu diketahui sifat partisipasi masyarakat lokal dalam pengelolaan wisata bahari di kawasan Turedawola Walo apakah mereka terlibat secara langsung atau tidak langsung dianalisis secara kuantitatif deskriptif dengan menggunakan analisis statistik: Uji MannWhitney (Uji- $U$ ) dengan bantuan program SPSS versi 19,0 for windows dari jawaban responden masyarakat lokal, maka kerangka pemikiran dibuat secara sistematis, seperti dalam Gambar 1 berikut:

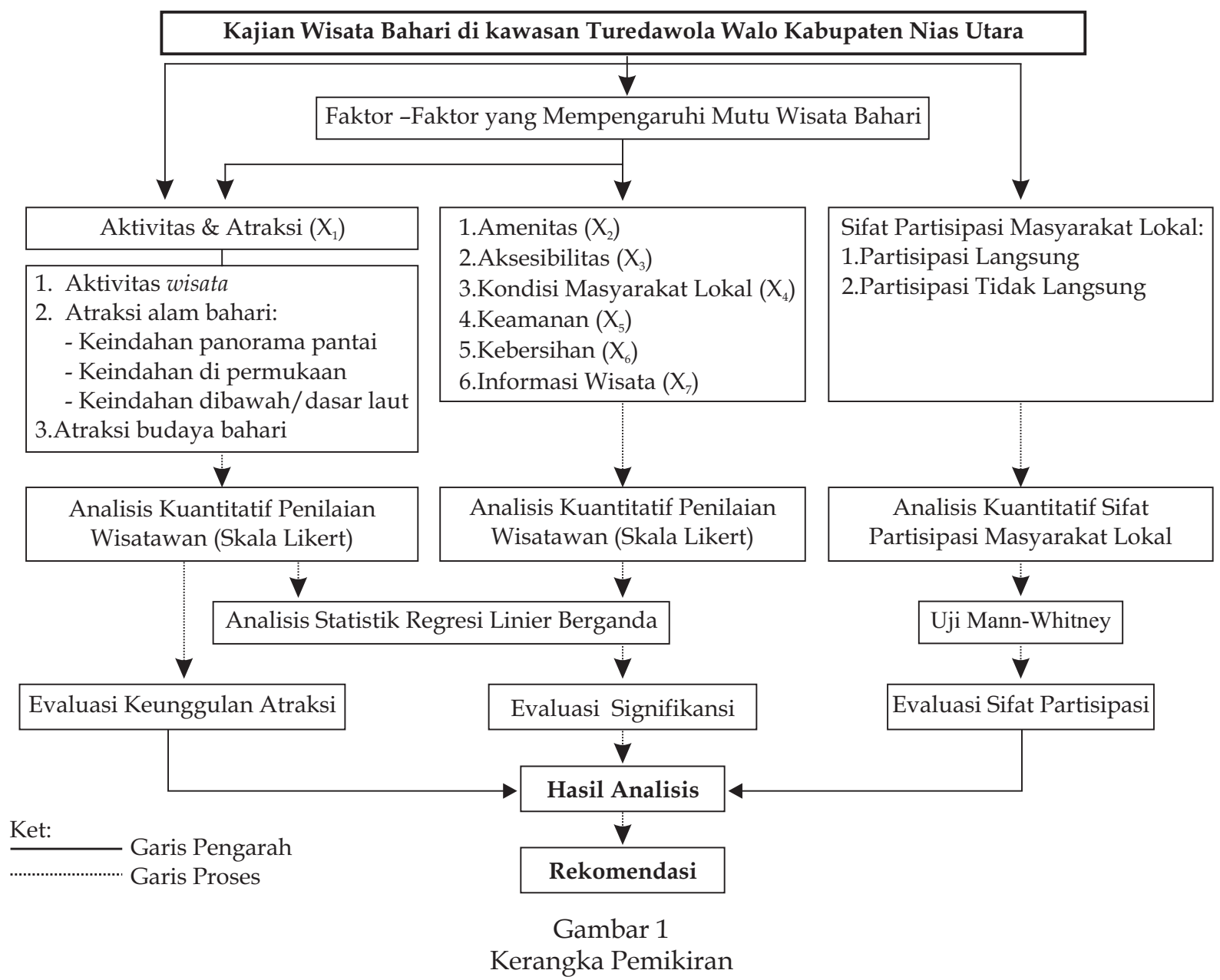


Hipotesis dalam penelitian ini terbagi atas 2 (dua) bagian, khususnya untuk rumusan masalah penelitian yang kedua dan ketiga adalah sebagai berikut:

Hipotesis Parsial $\left(\mathrm{h}_{1}-\mathrm{h}_{7}\right)$

$\mathrm{H}_{0}$ : Tidak ada pengaruh yang signifikan secara parsial antara $\left\{\left[h_{1}\right.\right.$ : aktivitas dan atraksi $\left.\left(\mathrm{X}_{1}\right) \rightarrow \mathrm{Y}\right] ; \quad\left[h_{2}:\right.$ amenitas $\left.\left(X_{2}\right) \rightarrow Y\right] ;\left[h_{3}\right.$ : aksesibilitas $\left.\left(X_{3}\right) \rightarrow Y\right] ;\left[h_{4}\right.$ : kondisi masyarakat lokal $\left(\mathrm{X}_{4}\right) \rightarrow \mathrm{Y}$; $\left[h_{5}\right.$ : keamanan $\left.\left(X_{5}\right) \rightarrow Y\right]$; $\left[h_{6}\right.$ : kebersihan $\left.\left(X_{6}\right) \rightarrow Y\right]$; dan $\left[h_{7}\right.$ : informasi wisata $\left.\left.\left(X_{7}\right) \rightarrow Y\right]\right\}$ terhadap Mutu Wisata Bahari di kawasan Turedawola Walo (Y).

$\mathrm{H}_{\mathrm{a}}$ : Ada pengaruh yang signifikan secara parsial antara $\left\{\left[h_{1}\right.\right.$ : aktivitas dan atraksi $\left.\left(\mathrm{X}_{1}\right) \rightarrow \mathrm{Y}\right] ;\left[h_{2}:\right.$ amenitas $\left.(\mathrm{X} 2) \rightarrow \mathrm{Y}\right] ;\left[h_{3}\right.$ : aksesibilitas $\left.\left(X_{3}\right) \rightarrow Y\right] ;\left[h_{4}\right.$ : kondisimasyarakat lokal $\left.\left(X_{4}\right) \rightarrow Y\right] ;\left[h_{5}\right.$ : keamanan $\left(X_{5}\right)$ $\rightarrow \mathrm{Y}] ;\left[h_{6}\right.$ : kebersihan $\left.\left(\mathrm{X}_{6}\right) \rightarrow \mathrm{Y}\right]$; dan $\left[h_{7}\right.$ : informasi wisata $\left.\left.\left(\mathrm{X}_{7}\right) \rightarrow \mathrm{Y}\right]\right\}$ terhadap Mutu Wisata Bahari di kawasan Turedawola Walo (Y).

Hipotesis Simultan $\left(\mathrm{h}_{8}\right)$

$\mathrm{H}_{0}$ : Tidak ada pengaruh yang signifikan secara simultan antara aktivitas dan atraksi, amenitas, aksesibilitas, kondisi masyarakat lokal, keamanan, kebersihan dan informasi wisata terhadap Mutu Wisata Bahari di kawasan Turedawola Walo.

$\mathrm{H}_{a}$ : Ada pengaruh yang signifikan secara simultan antara aktivitas dan atraksi, amenitas, aksesibilitas, kondisi masyarakat lokal, keamanan, kebersihan dan informasi wisata terhadap Mutu Wisata Bahari di kawasan Turedawola Walo.

Hipotesis untuk Sifat Partisipasi Masyarakat Lokal

$\mathrm{H}_{0}$ : Tidak ada perbedaan antara sifat Partisipasi Langsung (PL) dan Partisipasi Tidak Langsung (PTL).

$\mathrm{H}_{a}$ : Ada perbedaan antara sifat Partisipasi Langsung (PL) dan Partisipasi Tidak Langsung (PTL).

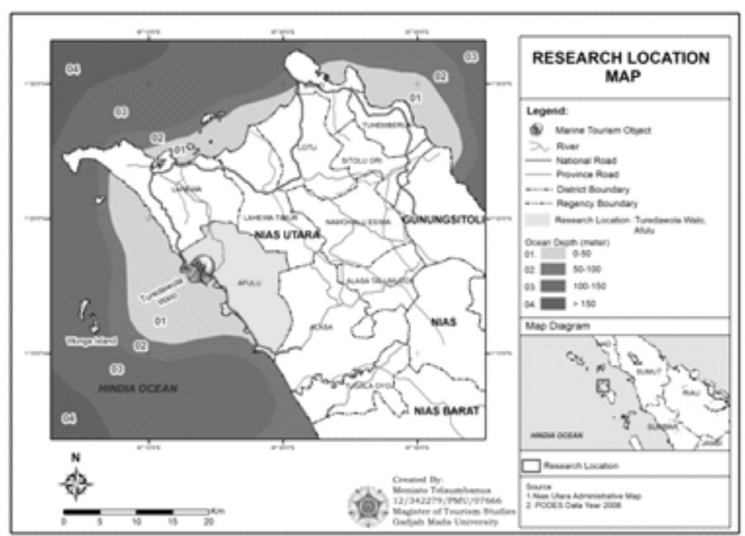

Source: Researcher Adaptation from

Administrative Map of Nias Utara Regency

Penelitian ini dilakukan di Desa Afulu, Kecamatan Afulu, Kabupaten Nias Utara dengan menggunakan metode penelitian deskriptif kuantitatif. Singarimbun dan Effendi (1989) menyatakan bahwa metode survai adalah salah satu metode penelitian yang mengambil sampel

dari suatu populasi dengan menggunakan kuesioner sebagai alat pengumpul data. Neuman (2013:55), penelitian survai menggunakan kuesioner tertulis untuk mengumpulkan informasi mengenai latar belakang, perilaku, keyakinan, atau sikap manusia dalam jumlah besar.

Sumber data penelitian: (1) data primer diperoleh langsung dari sumbernya, yaitu responden wisatawan (mancanegara dan domestik)/excursionists dan responden masyarakat lokal. Data primer diperoleh melalui survai (kuesioner), observasi dan dokumentasi langsung dilokasi penelitian; dan (2) data sekunder diperoleh dari berbagai instansi pemerintahan (pusat dan daerah) yaitu: BPS Nias, Bappeda Kabupaten Nias Utara, Disbudparpora Kabupaten Nias Utara, data dari Desa Afulu sebagai lokasi penelitian dan data lapangan milik peneliti, dan lain-lain.

Pengumpulan data dilakukan dengan menggunakan metode survai dengan alat pengumpul data kuesioner terhadap 63 responden wisatawan/excursionists yang secara kebetulan sedang berkunjung ke lokasi 
objek wisata di kawasan Turedawola Walo ditarik secara kebetulan (accidental sampling) dan 80 responden masyarakat lokal dengan acak keseluruhan (probability sampling) yang digunakan sebagai sampel.

Kuesioner untuk wisatawan (mancanegara dan domestik)/excursionists yakni: Pertama, kuesioner semi-terbuka digunakan untuk menjaring data demografi responden tentang umur, jenis kelamin, alamat, pendidikan, pekerjaan, daerah asal, dan data perilaku responden tentang cara memperoleh sumber informasi wisata, frekuensi dan durasi berwisata, alat transportasi yang digunakan, tempat menginap, dan lainlain. Kedua, kuesioner tertutup digunakan untuk penilaian wisatawan (mancanegara dan domestik)/excursionists terhadap: (1) aktivitas dan atraksi wisata bahari di kawasan Turedawola Walo guna mengevaluasi keunggulan atraksi. Kemudian hasil penilaian wisatawan terhadap atraksi dan aktivitas wisata $\left(X_{1}\right)$ tersebut dapat digunakan juga sebagai salah satu faktor pengaruh terhadap Y; dan (2) penilaian wisatawan (mancanegara dan domestik)/excursionists terhadap faktor pengaruh lainnya: dari $X_{2}$ hingga $X_{7}$ dalam bentuk kuesioner tertutup berskala Likert yang bergerak 1 hingga 5 .

Kuesioner untuk masyarakat lokal yakni: Pertama, kuesioner semi-terbuka digunakan untuk menjaring data demografi responden. Kedua, kuesioner tertutup digunakan untuk menjaring data dari masyarakat lokal tentang sifat partispasi masyarakat lokal (partisipasi langsung dan partisipasi tidak langsung). Selanjutnya, peneliti melakukan observasi langsung sekaligus mendokumentasikan hasil penelitian.

Teknik analisis data: Pertama, peneliti melakukan uji validitas dan reliabilitas dari jawaban responden wisatawan/excursionists berskala Likert yang bergerak dari 1 hingga 5 sesuai dengan item dalam kuesioner yang dapat dibuktikan dan dianalisis dengan melihat nilai/skor Corrected Item-Total Correlation sebagai nilai $\mathrm{r}$ hitung untuk uji validitas data dan nilai alpha cronbach (a) > 0,60 (Nunnally dalam Ghozali, 2006). Kriteria suatu instrument penelitian dikatakan reliable dengan menggunakan alpha cronbach, bila koefisien reliabilitas (r) > 0,6 (Siregar, 2010). Kedua, peneliti melakukan uji normalitas data dengan menggunakan Uji KolmogorovSmirnov. Tujuan uji normalitas terhadap serangkaian data adalah untuk mengetahui apakah populasi data berdistribusi normal atau tidak (Siregar, 2013:153).

Ketiga, untuk mengevaluasi keunggulan aktivitas dan atraksi, proses/tahapan pengolahan dan analisis data kuantitatif: (1) peneliti menghitung persentase dari hasil olahan masing-masing item parameternya; (2) peneliti menganalisis data dengan statistik deskriptif (descriptive statistics) untuk data keunggulan aktivitas dan atraksi wisata bahari melalui SPSS versi 19.00 for Windows untuk membuktikan standar minimum dan maksimal serta rata-rata hitung (mean) jawaban dari 63 responden dalam penelitian ini; dan (3) peneliti menyimpulkan keunggulan atraksinya. Keempat, untuk menganalisis pengaruh ketujuh predikator penelitian: (1) peneliti melakukan uji regresi linier berganda. Kusmayadi (2000:272), analisis regresi berganda (multiple regression analysis) merupakan teknik statistik yang secara simultan meneliti pengaruh dari dua atau lebih variabel bebas terhadap satu variabel terikat yang berskala interval atau rasio. Hipotesis parsial Regresi Linier Berganda dalam penelitian ini diuji dengan Uji- $t$ (Siregar, 2013:383). Hipotesis simultan Regresi Linier Berganda untuk analisis kuantitatif diuji dengan Uji-F (Siregar, 2013:447). Oleh karena itu, (2) peneliti membuktikan atau menguji hipotesis parsial $\left(h_{1}-h_{7}\right)$ dengan uji- $t$ dan hipotesis simultan $\left(h_{8}\right)$ dengan uji-F.

Kelima, untuk menganalisis perbedaan sifat partisipasi masyarakat lokal, maka peneliti menggunakan Uji Mann-Whitney (Uji-U). Martono (2010:6) menjelaskan bahwa statistik non-parametris adalah statistik yang digunakan untuk menganalisis data yang berskala nominal atau ordinal dari populasi yang bebas distribusi (tidak harus berdistribusi normal). Uji Mann-Whitney 
(Uji- $U$ ) dapat dipakai untuk menguji apakah dua kelompok independen telah ditarik dari populasi yang sama yang menunjukkan arah perbedaan (Siegel, 1997:145). Tes Mann-Whitney disebut juga $U j i-U$, sebagai alternatif dari uji $t$, bila asumsi-asumsi yang diperlukan untuk uji- $t$ tidak dijumpai (Kusmayadi, 2000:257).

\section{PEMBAHASAN \\ Kondisi Kawasan Wisata Bahari Turedawola Walo}

Kondisi fasilitas pendukung aktivitas wisata di kawasan Turedawola Walo tergolong sangat minim dan kurang memadai yang dapat dijelaskan melalui Tabel 2 berikut ini:

Tabel 2 Jenis Fasilitas Wisata yang Terdapat di Kawasan Turedawola Walo

\begin{tabular}{l|l|l}
\hline Lokasi & Jenis Fasilitas & Jumlah \\
\hline \multirow{2}{*}{ Daratan } & 1. Penginapan Citra & 1 unit (3 kamar) \\
\cline { 2 - 3 } & 2. Pondok Harianto & 1 unit (2 kamar) \\
\cline { 2 - 3 } & 3. Pamflet Wisata Walo & 1 unit \\
\hline \multirow{2}{*}{ Pantai } & 1. Pondok Payung Walo (Walo shelters) & 3 unit \\
\cline { 2 - 3 } & 2. Pondok Walo & 2 unit (2 kamar sederhana) \\
\cline { 2 - 3 } & 3. Pelabuhan/Dermaga Afulu & 1 unit \\
\hline \multirow{2}{*}{ Laut } & 1. Perahu Bermotor Afulu & 114 unit \\
\cline { 2 - 3 } & 2. Perahu Motor Tempel & 58 unit \\
\hline & 3. Kapal Bermotor Afulu & 2 unit \\
\hline
\end{tabular}

(Sumber: Hasil Survai, 2014)

\section{Penilaian Wisatawan/Excursionists terhadap Keunggulan Aktivitas dan Atraksi Wisata Bahari di kawasan Turedawola Walo}

Analisis statistik deskriptif (descriptive statistics) data keunggulan aktivitas dan atraksi wisata bahari di kawasan Turedawola
Walo diolah dengan menggunakan SPSS versi 19.00 for Windows untuk membuktikan standar minimum dan maksimal serta ratarata hitung (mean) jawaban dari 63 responden wisatawan/excursionist dalam penelitian ini, dapat disimak seperti tampak pada Tabel 3 berikut:

Tabel 3

Hasil Analisis Statistik Deskriptif Keunggulan Aktivitas dan Atraksi

\begin{tabular}{l|l|l|l|l|l}
\hline \multicolumn{1}{c|}{ AKTIVITAS \& ATRAKSI ( $\left.\mathbf{X}_{\mathbf{1}}\right)$} & $\mathbf{N}$ & Minimum & Maximum & Mean & Std. Deviation \\
\hline Selancar (Surfing) & 63 & 4 & 5 & $\mathbf{4 . 9 2}$ & .272 \\
Menyelam (Diving/Snorkeling) & 63 & 1 & 4 & 3.00 & .741 \\
Berenang (Swimming) & 63 & 2 & 5 & 3.22 & .659 \\
Memancing (Fishing) & 63 & 2 & 5 & 3.62 & .705 \\
Berlayar (Sailing) & 63 & 1 & 4 & 2.97 & .822 \\
Para-Layang (Kite-Surfing) & 63 & 1 & 4 & 3.00 & .741 \\
Berjemur (Sunbathing) & 63 & 2 & 5 & 3.71 & .728 \\
Mengamati Burung (Bird Watching) & 63 & 1 & 5 & 2.95 & .750 \\
Bersepeda Santai (Biking) & 63 & 1 & 5 & 3.37 & .789 \\
Berkemah (Camping) & 63 & 1 & 5 & 2.65 & .676 \\
\hline Aktivitas Wisata di Walo & 63 & 2.200 & 4.100 & 3.34127 & .346706 \\
\hline Ombak Besar dan Beruntun & 63 & 3 & 5 & 4.49 & .535 \\
Pulau Terluar Indonesia (Wunga) & 63 & 1 & 5 & 4.25 & .782 \\
Kondisi Air Laut Walo & 63 & 2 & 5 & 3.25 & .671 \\
\hline
\end{tabular}




\begin{tabular}{l|l|l|l|l|l}
\hline \multicolumn{1}{c|}{ AKTIVITAS \& ATRAKSI (X) } & N & Minimum & Maximum & Mean & Std. Deviation \\
\hline Atraksi Permukaan Laut di Walo & 63 & 2.333 & 4.667 & 4.00000 & .482675 \\
\hline Terumbu Karang (Coral Reef) & 63 & 2 & 5 & 3.62 & .728 \\
Rumput Laut (Sea Weeds) & 63 & 1 & 5 & 3.17 & .685 \\
Lobster & 63 & 3 & 5 & 4.11 & .675 \\
Kalimango (King Crabs) & 63 & 2 & 5 & 3.33 & .622 \\
Ikan Hias & 63 & 2 & 5 & 3.03 & .439 \\
Topografi Bawah Laut & 63 & 1 & 5 & 3.08 & .679 \\
\hline Atraksi Dasar Laut di Walo & 63 & 2.667 & 4.500 & 3.39153 & .397301 \\
\hline Pasir Putih (White Sand) & 63 & 3 & 5 & 3.87 & .684 \\
Vegetasi Pantai & 63 & 2 & 5 & 3.57 & .665 \\
Panorama Pagi Hari (Sunrise) & 63 & 2 & 5 & 3.03 & .671 \\
Panorama Senja (Sunset) & 63 & 3 & 5 & 4.43 & .560 \\
\hline Atraksi Panorama Pantai di Walo & 63 & 2.750 & 5.000 & 3.72619 & .483006 \\
\hline Tari Maena & 63 & 1 & 5 & 4.33 & .718 \\
Upacara Adat Nias Utara & 63 & 1 & 5 & 3.71 & .728 \\
Anyaman Tikar \& Bola Nafo & 63 & 1 & 5 & 3.78 & .728 \\
Alat Musik Tradisional & 63 & 1 & 5 & 4.11 & .743 \\
Nias Living Language & 63 & 3 & 5 & 4.14 & .715 \\
\hline Atraksi Budaya Bahari di Walo & 63 & 1.800 & 5.000 & 4.01587 & .508383 \\
\hline RATA-RATA NILAI AKTIVITAS \& & 63 & 3.087 & 4.353 & 3.69497 & .308518 \\
ATRAKSI DI KAWASAN WALO & & & & & \\
\hline
\end{tabular}

(Sumber: Hasil Pengolahan Data Primer, 2014)

Tabel 3 menunjukkan bahwa jenis aktivitas dan atrkasi wisata di kawasan Turedawola Walo yang paling unggul adalah aktivitas selancar (surfing) dengan rata-rata nilai sebesar 4,92 . Nilai rata-rata hitung (mean) dari keseluruhan jenis aktivitas dan atraksi wisata Turedawola Walo adalah sebesar 3,694 dengan kategori "menarik". Asumsi ini dapat juga dibuktikan seperti terurai dalam Tabel 4 berikut:

Tabel 4

Finalisasi Evaluasi Keunggulan Aktivitas dan Atraksi

\begin{tabular}{c|l|r|r}
\hline \multicolumn{2}{c|}{ Aktivitas \&Atraksi } & Frekuensi & Persentase \\
\hline \multirow{4}{*}{ Valid } & Cukup Menarik & 12 & 19.0 \\
\cline { 2 - 4 } & Menarik & 47 & 74.6 \\
\cline { 2 - 4 } & Sangat Menarik & 4 & 6.3 \\
\cline { 2 - 4 } & Total & 63 & 100.0 \\
\hline
\end{tabular}

(Sumber: Hasil Pengolahan Data Primer, 2014)
Tabel 4

Finalisasi Evaluasi Keunggulan Aktivitas dan Atraksi

\begin{tabular}{l|l|r|r}
\hline \multicolumn{2}{|l|}{ Surfing } & Frequency & Percent \\
\hline Valid & Menarik & 5 & 7.9 \\
\cline { 2 - 4 } & Sangat Menarik & 58 & 92.1 \\
\cline { 2 - 4 } & Total & 63 & 100.0 \\
\hline
\end{tabular}

(Sumber: Hasil Pengolahan Data Primer, 2014)

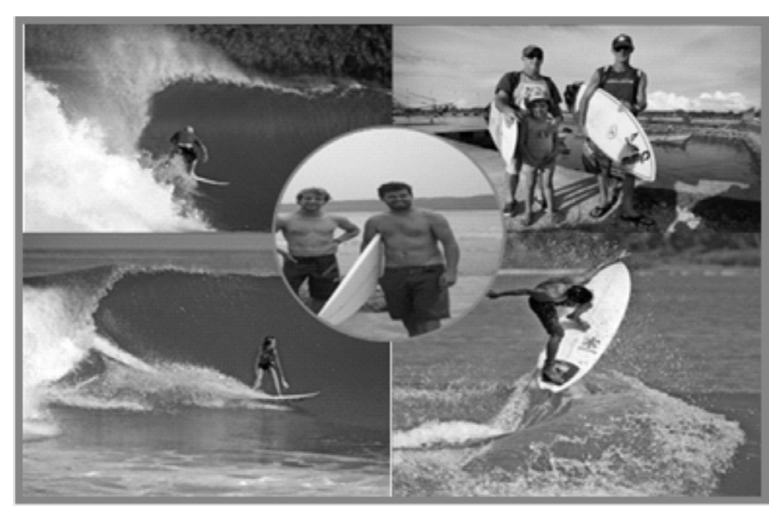

Gambar 2 Aktivitas Surfing di Walo (Sumber: Dokumentasi Penulis, 2014) 
Tabel 5 menunjukkan bahwa aktivitas wisata di kawasan Turedawola Walo yang paling unggul adalah aktivitas selancar (surfing) sebesar 92,1\% atau 58 dari 63 responden wisatawan (domestik dan mancanegara)/excursionists menilai aktivitas surfing dengan indikator "sangat menarik". Keinginan para turis untuk berselancar seakan menjadi candu yang mendorong banyak wisatawan mengeksplorasi spot .

terbaik untuk menaklukkan gulungan ombak dan menyalurkan hasrat dan hobi berselancar sekaligus berolahraga di Turedawola Walo. Peselancar dari belahan dunia manapun dapat menikmati aksi petualangan dan bermanuver di atas ombak tropis yang beruntun bertipe left-hander wave, seperti terlihat pada Gambar 2 di atas.

\section{Penilaian Wisatawan/Excursionists terhadap Faktor-Faktor yang mempengaruhi Mutu Wisata Bahari di kawasan Turedawola Walo}

\section{(a) Distribusi Frekuensi Kuantitatif Tujuh Variabel Bebas}

Kriteria pembulatan rata-rata skor ketujuh predikator (variabel bebas) sebagaimana terurai dalam Tabel 6, penulis berpedoman pada skala Likert interval skornya adalah sebagai berikut:

Tabel 6

\begin{tabular}{l|l|l|l}
\hline \multirow{2}{*}{ Interval Skor } & \multicolumn{3}{c}{ Keterangan } \\
\cline { 2 - 4 } & \multicolumn{1}{c|}{ Parameter I } & \multicolumn{1}{c}{ Parameter II } & \multicolumn{1}{c}{ Parameter III } \\
\hline $1-1,79$ & Sangat Tidak Menarik & Sangat Jelek & Sangat Tidak Ramah \\
\hline $1,80-2,59$ & Tidak Menarik & Jelek & Tidak Ramah \\
\hline $2,60-3,39$ & Cukup Menarik & Cukup Bagus & Cukup Ramah \\
\hline $3,40-4,19$ & Menarik & Bagus & Ramah \\
\hline $4,20-5,00$ & Sangat Menarik & Sangat Bagus & Sangat Ramah \\
\hline
\end{tabular}

Tabel 7

Distribusi Frekuensi Kuantitatif Penilaian Wisatawan/Excursionists

\begin{tabular}{|c|c|c|c|}
\hline \multicolumn{2}{|c|}{ Faktor-Faktor Pengaruh terhadap Mutu Wisata Bahari Turedawöla Walo } & \multirow{2}{*}{\begin{tabular}{|l|} 
Frekuensi \\
12
\end{tabular}} & \multirow{2}{*}{\begin{tabular}{|l} 
Persentase \\
19.0
\end{tabular}} \\
\hline Aktivitas dan Atraksi $\left(X_{1}\right)$ & Cukup Menarik & & \\
\hline & Menarik & 47 & 74.6 \\
\hline & Sangat Menarik & 4 & 6.3 \\
\hline \multirow[t]{4}{*}{ Amenitas $\left(X_{2}\right)$} & Jelek & 15 & 23.8 \\
\hline & Cukup Bagus & 40 & 63.5 \\
\hline & Bagus & 7 & 11.1 \\
\hline & Sangat Bagus & 1 & 1.6 \\
\hline \multirow[t]{4}{*}{ Aksesibilitas $\left(X_{3}\right)$} & Jelek & 2 & 3.2 \\
\hline & Cukup Bagus & 13 & 20.6 \\
\hline & Bagus & 46 & 73.0 \\
\hline & Sangat Bagus & 2 & 3.2 \\
\hline \multirow[t]{3}{*}{ Kondisi Masyarakat Lokal $\left(\mathrm{X}_{4}\right)$} & Cukup Ramah & 5 & 7.9 \\
\hline & Ramah & 23 & 36.5 \\
\hline & Sangat Ramah & 35 & 55.6 \\
\hline \multirow[t]{3}{*}{ Keamanan $\left(X_{5}\right)$} & Cukup Bagus & 24 & 38.1 \\
\hline & Bagus & 34 & 54.0 \\
\hline & Sangat Bagus & 5 & 7.9 \\
\hline
\end{tabular}




\begin{tabular}{l|l|l|l}
\hline \multicolumn{2}{l|}{ Faktor-Faktor Pengaruh terhadap Mutu Wisata Bahari Turedawöla Walo } & Frekuensi & Persentase \\
\hline \multirow{2}{*}{ Kebersihan $\left(X_{6}\right)$} & Sangat Jelek & 60 & 95.2 \\
\cline { 2 - 4 } & Jelek & 3 & 4.8 \\
\hline \multirow{2}{*}{ Informasi Wisata $\left(X_{7}\right)$} & Sangat Jelek & 58 & 92.1 \\
\cline { 2 - 4 } & Jelek & 5 & 7.9 \\
\hline Jumlah & 63 & 100.00 \\
\hline
\end{tabular}

(Sumber: Pengolahan Data Primer, 2014)

(b) Hasil Uji Regresi Linier Berganda Tujuh Prediktor Analisis regresi linier berganda digunakan untuk mengetahui pengaruh variabel bebas $(X)$ terhadap variabel tergantungnya $(\mathrm{Y})$, sebagai berikut:

Tabel 8

Hasil Uji Regresi Linier Berganda

\begin{tabular}{|c|c|c|c|c|c|}
\hline \multirow[t]{2}{*}{ Model } & & \multicolumn{2}{|c|}{$\begin{array}{c}\text { Unstandardized } \\
\text { Coefficients }\end{array}$} & \multirow[t]{2}{*}{$\mathrm{T}$} & \multirow[t]{2}{*}{ Sig. } \\
\hline & & B & $\begin{array}{l}\text { Std. } \\
\text { Error }\end{array}$ & & \\
\hline & (Constant) & 9.122 & 6.027 & 1.514 & .136 \\
\hline & $x_{1}$ & .135 & .048 & 2.816 & .007 \\
\hline & $X_{2}$ & -.215 & .159 & -1.357 & .180 \\
\hline & $X_{3}$ & \begin{tabular}{|l|l|}
.429 \\
\end{tabular} & \begin{tabular}{|l|}
.209 \\
\end{tabular} & 2.054 & .045 \\
\hline & $X_{4}$ & .576 & .223 & 2.584 & .012 \\
\hline & $X_{5}$ & .492 & .209 & 2.361 & .022 \\
\hline & $x_{6}$ & -.604 & .374 & -1.615 & .112 \\
\hline & $X_{7}$ & -.002 & .359 & -.005 & .996 \\
\hline
\end{tabular}

(Sumber: Pengolahan Data Primer, 2014)

Dari hasil uji regresi linier berganda pada Tabel 7 secara matematis dapat disusun persamaan regresi berganda sebagai berikut:

$Y=9,122+0,135 X_{1}-0,215 X_{2}+0,429 X_{3}+$ $0,576 X_{4}+0,492 X_{5}-0,604 X_{6}-0,002 X_{7}$

Konstanta (a) sebesar 9,122 artinya besarnya nilai Mutu Wisata Bahari sebesar 9,122 dengan asumsi faktor-faktor lain konstan yang dalam hal ini $X_{1}$ (Aktivitas dan Atraksi), $X_{2}$ (Amenitas), $X_{3}$ (Aksesibilitas), $X_{4}$ (Kondisi Masyarakat Lokal), $X_{5}$ (Keamanan), $X_{6}$ (Kebersihan), dan $X_{7}$ (Informasi Wisata), adalah sebesar nol. Pertama, koefisien regresi variabel $X_{1}\left(b_{1}\right)$ bernilai positif yaitu sebesar 0,135 , artinya bahwa setiap peningkatan $X_{1}$ sebesar 1 (satu) satuan akan meningkatkan Y sebesar 0,135. Kedua, $\left(b_{2}\right)$ bernilai negatif yaitu sebesar $(-0,215)$, artinya bahwa setiap penurunan $X_{2}$ sebesar 1 (satu) satuan akan menurunkan Y sebesar $(-0,215)$. Ketiga, $\left(b_{3}\right)$ bernilai positif yaitu sebesar 0,429 , artinya bahwa setiap peningkatan $X_{3}$ sebesar 1 (satu) satuan akan meningkatkan $Y$ sebesar 0,429. Keempat, $\left(b_{4}\right)$ bernilai positif yaitu sebesar 0,576, artinya bahwa setiap peningkatan $\mathrm{X}_{4}$ sebesar 1 (satu) satuan akan meningkatkan $Y$ sebesar 0,576 . Kelima, $\left(b_{5}\right)$ bernilai positif yaitu sebesar 0,492, artinya bahwa setiap peningkatan $X_{5}$ sebesar 1 (satu) satuan akan meningkatkan $\mathrm{Y}$ sebesar 0,492. Keenam, $\left(b_{6}\right)$ bernilai negatif yaitu sebesar $(-0,604)$, artinya bahwa setiap penurunan $X_{6}$ sebesar 1 (satu) satuan akan menurunkan Y sebesar $(-0,604)$. Ketujuh, $\left(b_{7}\right)$ bernilai negatif yaitu sebesar $(-0,002)$, artinya bahwa setiap penurunan $X_{7}$ sebesar 1 (satu) satuan akan menurunkan $Y$ sebesar $(-0,002)$. Ketujuh variabel bebas ini merupakan indikator penting dalam mengembangkan wisata bahari di Turedawola Walo Kabupaten Nias Utara. Untuk memahami hasil kontribusi masing-masing variabel bebas terhadap variabel terikat $(\mathrm{Y})$ dapat diilustrasikan pada Gambar 3 berikut:

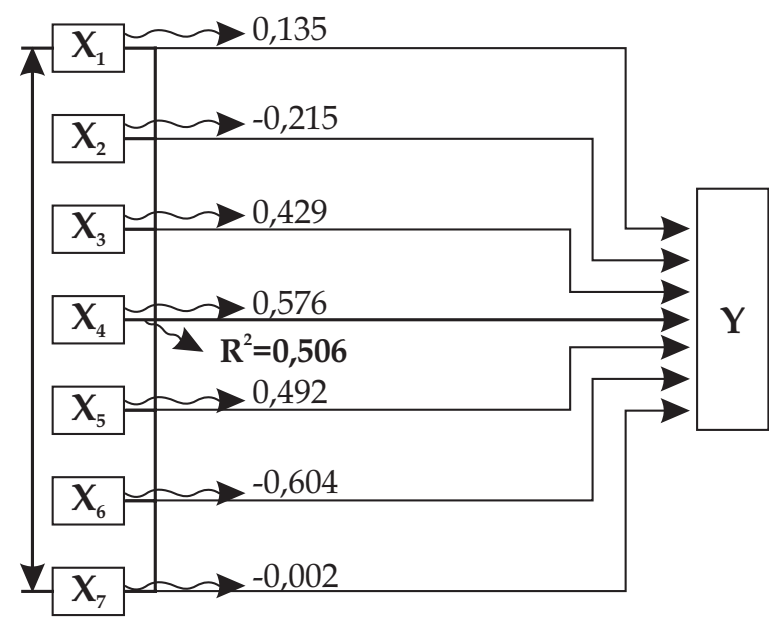

Gambar 3 Hasil Kontribusi Variabel Bebas Terhadap Y 
(c) Hasil Pengujian Hipotesis Simultan (Uji-F) Regresi Linier Berganda

Tabel 9 Hasil Uji F

\begin{tabular}{l|l|l|l|l|l}
\hline Model & Sum of Squares & Df & Mean Square & F & Sig. \\
\hline 1. Regression & 376.097 & 7 & 53.728 & 8.045 & $.000(\mathrm{a})$ \\
Residual & 367.332 & 55 & 6.679 & & \\
Total & 743.429 & 62 & & & \\
\hline
\end{tabular}

(Sumber: Pengolahan Data Primer, 2014)

Tabel 8 menunjukkan bahwa nilai $\mathrm{F}$ hitung $>$ F tabel $(8,045>2,181)$ dan signifikansi $<0,05(0,000<0,05)$, artinya bahwa variabel $X_{1}$ (Aktivitas dan Atraksi), $X_{2}$ (Amenitas), $X_{3}$ (Aksesibilitas), $X_{4}$ (Kondisi MasyarakatLokal), $X_{5}$ (Keamanan), $X_{6}$ (Kebersihan), dan $X_{7}$ (Informasi Wisata) secara simultan berpengaruh terhadap Mutu Wisata Bahari Turedawola Walo (Y). (d) Hasil Pengujian Hipotesis Parsial dan Uji Signifikansi (Uji-t) Regresi Linier Berganda Hasil perbandingan nilai uji-t dan nilai $t$-tabel pada pengujian regresi linier berganda dalam penelitian ini dapat disimak pada Tabel 9 berikut:

Tabel 10 Hasil Perbandingan Nilai Uji- $t$ hitung dan Nilai $t$-tabel

\begin{tabular}{l|l|l|l|l|l}
\hline \multirow{2}{*}{ Var. } & \multirow{2}{*}{$\begin{array}{c}\text { Nilai } \\
\text {-hitung }\end{array}$} & \multirow{2}{*}{ Simbol } & \multirow{2}{*}{$\begin{array}{c}\text { Nilai } \\
\text {-tabel }\end{array}$} & & \multicolumn{2}{c}{$\mathbf{H}_{0}$} & \multicolumn{1}{c}{ Interpretasi Hasil } \\
\cline { 5 - 6 } & & & & \multicolumn{1}{c}{ Keterangan } \\
\hline$X_{1}$ & 2,816 & $>$ & 1,999 & Ditolak & Ada pengaruh \\
\hline$X_{3}$ & $-1,357$ & $<$ & 1,999 & Diterima & Tidak ada pengaruh \\
\hline$X_{4}$ & 2,054 & $>$ & 1,999 & Ditolak & Ada pengaruh \\
\hline$X_{5}$ & 2,584 & $>$ & 1,999 & Ditolak & Ada pengaruh \\
\hline$X_{6}$ & 2,361 & $>$ & 1,999 & Ditolak & Ada pengaruh \\
\hline$X_{7}$ & $-1,615$ & $<$ & 1,999 & Diterima & Tidak ada pengaruh \\
\hline
\end{tabular}

(Sumber: Analisis Data Primer, 2014)

Hasil perbandingan nilai signifikansi hipotesis parsial (uji-t) dan nilai taraf nyata (a) pada regresi linier berganda, dapat dijelaskan pada Tabel 10 berikut:

Tabel 11 Hasil Perbandingan Nilai Sig. t-hit (Prob. Value) dan Nilai (a)

\begin{tabular}{l|l|l|l|l|l}
\hline \multirow{2}{*}{ Var. } & \multirow{2}{*}{$\begin{array}{c}\text { Nilai } \\
\text { Sig. } \boldsymbol{t} \text {-hit }\end{array}$} & \multirow{2}{*}{ Simbol } & \multirow{2}{*}{$\begin{array}{c}\text { Nilai } \\
\text { (a) }\end{array}$} & & \multicolumn{2}{c}{$\mathbf{H}_{0}$} & \multicolumn{1}{c}{ Interpretasi Hasil } \\
\cline { 5 - 6 } & & & & \multicolumn{2}{c}{ Keterangan } \\
\hline$X_{1}$ & 0,007 & $<$ & 0,05 & Ditolak & Ada pengaruh \\
\hline$X_{2}$ & 0,180 & $>$ & 0,05 & Diterima & Tidak ada pengaruh \\
\hline$X_{3}$ & 0,045 & $<$ & 0,05 & Ditolak & Ada pengaruh \\
\hline$X_{4}$ & 0,012 & $<$ & 0,05 & Ditolak & Ada pengaruh \\
\hline$X_{5}$ & 0,022 & $<$ & 0,05 & Ditolak & Ada pengaruh \\
\hline$X_{6}$ & 0,112 & $>$ & 0,05 & Diterima & Tidak ada pengaruh \\
\hline$X_{7}$ & 0,996 & $>$ & 0,05 & Diterima & Tidak ada pengaruh \\
\hline
\end{tabular}

(Sumber: Analisis Data Primer, 2014)

Perbedaan Sifat Partisipasi Masyarakat Lokal di kawasan Turedawola Walo

Hasil uji Mann-Whitney untuk sifat partisipasi masyarakat lokal, dengan taraf signifikansi $(a=0,05)$, dapat disimak pada Tabel 11 berikut: 
Tabel 12 Hasil Uji Mann-Whitney

\begin{tabular}{|c|c|c|c|c|c|c|}
\hline & ifat Partisipasi & $\mathbf{N}$ & $\begin{array}{l}\text { Rata-Rata } \\
\text { (Mean) }\end{array}$ & $\begin{array}{c}\mathrm{R} \\
\text { (Rangking) }\end{array}$ & $\begin{array}{c}\text { Mann-Whitney } \\
\text { U } \\
\end{array}$ & $\begin{array}{c}\text { Prob. Value (Sig. } \\
\text { 2-tailed) }\end{array}$ \\
\hline Sko & $\begin{array}{l}\text { Langsung } \\
\text { Tidak Langsung }\end{array}$ & $\begin{array}{l}80 \\
80\end{array}$ & $\begin{array}{l}1,175 \\
1,500\end{array}$ & $\begin{array}{l}5620,50 \\
7259,50\end{array}$ & 2380,5 & 0,004 \\
\hline
\end{tabular}

(Sumber: Pengolahan Data Primer, 2014)

Tabel 12 menunjukkan bahwa nilai uji Mann-Whitney (U) berdasarkan perhitungan program SPSS 19.0 for windows untuk sifat partisipasi dari 80 responden masyarakat lokal Desa Afulu dalam pengelolaan lokasi wisata bahari Turedawola Walo sebesar $\mathrm{U}=2.380,5$ dengan nilai signifikasi (prob. value) U hitung sebesar 0,004 . Skor rata-rata (Mean Rank) untuk sifat Partisipasi Langsung (PL) sebesar 1,175, sedangkan untuk sifat Partisipasi Tidak Langsung sebesar 1,500, artinya PTL $(1,500)>$ PL $(1,175)$. Selanjutnya skor/nilai (R) rangking (Sum of Ranks) untuk sifat Partisipasi Langsung (PL) sebesar 5.620,5, sedangkan untuk sifat Partisipasi Tidak Langsung sebesar 7.259,5.

Perbedaan nilai rata-rata (Mean Rank) dan rangking (Sum of Ranks) antara kedua sifat partisipasi ini jelas menunjukkan bahwa $\mathrm{H}_{0}$ dalam penelitian ini harus ditolak, dan $H_{a}$ diterimakarenaternyataadaperbedaanantara sifat Partisipasi Langsung dan Partisipasi Tidak Langsung $\left(\mathrm{x}_{1}=1,175<\mathrm{x}_{2}=1,500\right.$ dan $\mathrm{R}_{1}$ $\left.5.620,5<R_{2} 7.259,5\right)$ dengan asumsi bahwa $H_{0}$ juga ditolak karena nilai signifikasi (prob. value) U hitung sebesar $(0,004)<a(0,05)$. Kesimpulannya adalah sifat partisipasi tidak langsung lebih besar dibanding dengan sifat partisipasi langsungnya, artinya masyarakat Desa Afulu masih sedikit terlibat secara langsung dalam pengelolaan lokasi wisata bahari Turedawola Walo.

Berdasarkan hasil evaluasi keunggulan aktivitas dan atraksi wisata bahari di kawasan Turedawola Walo, penulis bisa menjelaskan bahwa aktivitas surfing merupakan aktivitas andalan dan unggulan yang bisa memikat hati penggemar wisata olahraga ini baik wisatawan mancanegara maupun wisatawan domestik karena aktivitas dan atraksi surfing (selancar) di kawasan Turedawola Walo berstandar internasional; dan situasi ini juga didukung oleh kondisi masyarakat lokal yang bisa dikategorikan ramah dalam berinteraksi dengan para wisatawan atau tamu yang berkunjung ke lokasi. Variabel kondisi masyarakat lokal dalam penelitian ini merupakan variabel yang dominan dan mempunyai nilai kontribusi paling besar $(0,576)$ terhadap Mutu Wisata Bahari; namun demikian, berdasarkan hasil survai/temuan dilapangan bahwa potensi aktivitas surfing ini memiliki juga beberapa kelemahan yaitu kurangnya sarana dan prasarana pendukung wisata di kawasan Turedawola Walo.

Beberapa kelemahan ditemukan dilapangan selama penelitian yaitu (1) kurangnya sarana dan prasarana pendukung aktivitas dan atraksi wisata, misalnya: toko/ tempat persewaan papan selancar/alat surfing (tidak tersedia), alat selam/diving (tidak tersedia) yang biasanya disediakan/ dibawa oleh para peselancar itu sendiri; (2) akomodasi/penginapan khususnya di lokasi wisata (tersedia tetapi sangat sederhana) yang terbuat dari papan dengan jumlah kamar sebanyak 2 unit saja yang dilengkapi dengan kelambu, kasur dan listrik, namun kipas angin tidak tersedia di dalam kamar dan tidak berkamar mandi; (3) sarana dan prasarana kebersihan lokasi wisata seperti: toilet umum (tidak tersedia), tong sampah (tidak tersedia), petugas kebersihan wisata (tidak ada), dan lain-lain; dan (4) sumber informasi tentang wisata Turedawola Walo sangat terbatas misalnya: leaflet/brosur wisata (belum tersedia); buku panduan (guide book) juga belum tersedia; informasi via internet (tersedia, tetapi masih minim); pamflet wisata (tersedia, tetapi kurang jelas dalam menunjukkan arah lokasi).

Berdasarkan hasil analisis perbedaan sifat partispasi masyarakat lokal di kawasan Turedawola Walo bahwa mayoritas 
masyarakat Desa Afulu hanya berpartisipasi secara tidak langsung karena mayoritas mereka bermata-pencaharian sebagai petani dan nelayan yang secara tidak langsung mendukung kegiatan pawisata di kawasan Turedawola Walo seperti: sebagai supplier (penyedia) bahan makanan dan minuman atau bahan pangan (beras, sayur-mayur, buah-buahan, daging, ikan, lobster, dan lain-lain), sebagai supplier (penyedia) bahan bangunan (ijuk, kayu, bambu, dan lain-lain). Masyarakat setempat yang berada di kawasan Turedawola Walo merupakan pihak yang paling dekat dengan permasalahan lingkungan yang terjadi, sehingga masyarakat merupakan kunci dari keberhasilan pengelolaan lingkungan kawasan wisata Turedawola Walo.

\section{SIMPULAN}

Berdasarkan hasil penelitian diketahui bahwa: (1) aktivitas dan atraksi wisata yang paling unggul di kawasan Turedawola Walo adalah surfing; (2) variabel amenitas, kebersihan dan informasi wisata tidak berpengaruh secara signifikan terhadap Mutu Wisata Bahari di kawasan Turedawola Walo, sedangkan variabel aktivitas dan atraksi, aksesibilitas, kondisi masyarakat lokal, dan keamanan berpengaruh secara signifikan terhadap Mutu Wisata Bahari di kawasan Turedawola Walo; dan (3) perbedaan sifat partisipasi masyarakat diketahui bahwa partisipasi tidak langsung lebih besar daripada partisipasi langsung yang menandakan bahwa mayoritas masyarakat lokal Desa Afulu berpartisipasi secara tidak langsung terhadap pengelolaan wisata bahari Turedawola Walo Kabupaten Nias Utara.

Berdasarkan hasil penelitian, maka saran yang dapat disampaikan sebagai berikut: (1) pemerintah, masyarakat setempat, dan pemangku kepentingan (stakeholders) pariwisata perlu berkolaborasi dalam mengupayakan secara serius kelayakan sarana dan prasarana pendukung aktivitas wisata di lokasi Turedawola Walo, terutama amenitas, kebersihan dan informasi serta meningkatkan kualitas pelayanan (better service) di lokasi wisata demi kenyamanan wisatawan yang berkunjung; (2) keterlibatan masyarakat lokal secara langsung harus ditingkatkan melalui pembangunan pariwisata berkelanjutan (tourism sustainable development) karena masyarakat merupakan salah kunci pokok dalam pengelolaan wisata bahari Turedawola Walo dan mengingat manfaat ekonomi masih minim dan belum menyejahterakan masyarakat sendiri; (3) karya ilmiah ini dapat diteruskan oleh peneliti berikutnya karena menyumbang pemikiran wisata bahari karena Indonesia merupakan negara kepulauan dan $2 / 3$ wilayahnya adalah perairan, terutama untuk meneliti dari perspektif wisatawannya; (4) penulis menyarankan bahwa prinsip keseimbangan dan keselarasan antara kepentingan berbagai stakeholders pembangunan pariwisata termasuk pemerintah, swasta dan masyarakat perlu ditekankan pada pembangunan pariwisata yang bersifat demokratis yaitu:"dari masyarakat, oleh masyarakat dan untuk masyarakat" dan mempertahankan nilai kearifan lokal serta nilai ekowisata yang berbasis alam.

\section{DAFTAR PUSTAKA}

Baiquni, M. 2004. Membangun Pusat-Pusat di Pinggiran: Otonomi di Negara Kepulauan. Yogyakarta: Penerbit ideAs dan PKPEK.

BPS Kabupaten Nias. 2013. Nias Utara Dalam Angka (Nias Utara in Figures).

Damanik, J dan Helmut F. Weber. 2006. Perencanaan Ekowisata dari Teori ke Aplikasi. Yogyakarta: Penerbit ANDI. dan Frans Teguh. 2012. Manajemen Destinasi Pariwisata: Sebuah Pengantar Ringkas. Yogyakarta: Kepel Press.

Dinas Kebudayaan, Pariwisata, Pemuda dan Olahraga Kabupaten Nias Utara. 2013. Buku Sekilas Potensi Wisata dan Budaya Kabupaten Nias Utara.

Fandeli, C. 1996. Pengusahaan Ekowisata. Yogyakarta: Pustaka Pelajar. 
2001. Dasar-Dasar Manajemen Kepariwisataan Alam. Yogyakarta: Liberty.

Ghozali, Imam H. 2006. Aplikasi Analisis Multivariate dengan Program SPSS. Badan Penerbit Universitas Diponegoro (UNDIP).

Idris, I. Sapta Putra. G. dan Budiman. 2007. Membangun Ekonomi Raksasa: Sebuah Kajian terhadap Perundang-Undangan Pengelolaan Wilayah Pesisir dan Pulau-Pulau Kecil. Bogor: PT. Sarana Komunikasi Utama.

Jennings, G., 2007, Water-Based Tourism, Sport, Leisure, and Recreation Experiences, Elsevier Inc, All rights Reserves.

Kusmayadi dan Sugiarto, E., 2000, Metodologi Penelitian dalam Bidang Kepariwisataan, Jakarta: PT. Gramedia Pustaka Utama.

Mann, K.H. 1982. Ecology of Coastal Waters: A System Approach, 322p. In Anderson, D.J., P. Greic-Smith, and F.A.Pitelka (eds.) Studies in Ecology, Vol 8. University of California Press, California.

Martono, Nanang. 2010. Statistik Sosial: Teori dan Aplikasi Program SPSS. Yogyakarta: Penerbit Gava Media.

Neuman, W.Lawrence. 2013. Metodologi Penelitian Sosial: Pendekatan Kualitatif dan Kuantitatif. Eds.7. Penerjemah: Edina T. Sofia. Jakarta: PT.Indeks.

Numberi, Freddy. 2009. Perubahan Iklim, Implikasinya terhadap Kehidupan di Laut, Pesisir, dan Pulau-Pulau Kecil. Jakarta: Fortuna Prima Makmur.

Nurisyah, S., Sunatno, dan Sarwinto Hadi. 2004. Pedoman Pengembangan Wisata Bahari Berbasis Masyarakat di Kawasan Konservasi Laut. Jakarta: Direktorat Konservasi dan Taman Nasional Laut, Direktorat Jenderal Pesisir dan Pulau-Pulau Kecil, Departemen Kelautan dan Perikanan.

Pitana, I G. dan Diarta, K.S., 2009, Pengantar Ilmu Pariwisata, Yogyakarta: C.V ANDI Offset.

Siegel, Sidney. 1997. Statistik Nonparametrik untukIlmu-Ilmu Sosial.Diterjemahkan oleh: Zanzawi Suyuti dan Landung Simatupang. Jakarta: Penerbit PT Gramedia Pustaka Utama.

Singarimbun, M. dan Sofian Effendi. 1989. Metode Penelitian Survai. Jakarta: LP3ES.

Siregar, Syofian. 2010. Statistika Deskriptif untuk Penelitian: Dilengkapi Perhitungan Manual dan Aplikasi SPSS versi 17. Jakarta: PT. RajaGrafindo Persada.

. 2013. Statistik Parametrik untuk Penelitian Kuantitatif: Dilengkapi Perhitungan Manual dan Aplikasi SPSS versi 17. Jakarta: Penerbit Bumi Aksara.

Spillane,James.J.1994. Pariwisata Indonesia Siasat Ekonomi dan Rekayasa Kebudayaan. Yogyakarta: Penerbit Kanisius.

Suwena, I Ketut dan I Gusti Widyatmaja. 2010. Pengetahuan Dasar Ilmu Pariwisata. Denpasar: Udayana University Press.

Surat Keputusan Bupati Nias Utara Nomor: 556/219/K/Tahun 2013 tanggal 13 September 2013 tentang Penetapan Lokasi Objek Wisata dan Rekreasi di Kabupaten Nias Utara.

Undang-Undang Republik Indonesia Nomor 45 Tahun 2008 tentang Pembentukan Kabupaten Nias Utara di Provinsi Sumatera Utara.

Undang-Undang Republik Indonesia Nomor 10 Tahun 2009 tentang Kepariwisataan. 